polymyositis may have converted an otherwise trivial infection into the dramatic and alarming episode we witnessed. Secondly, periorbital swelling due to dermatomyositis may have been the predisposing factor, but no other stigmata of this condition and no cause for it could be found. The myositis was not due to the steroid treatment as it varied inversely with steroid dose, and its persistence shows that it was not a "toxic" effect of the acute illness.

${ }^{1}$ Meleney, F. L., Archives of Surgery, 1924, 9, 317.

2 Fallahzadeh, H., Altenbernd, E., and Mays, E. T., American Surgeon, $1972,40,352$.

${ }^{3}$ Beathard, G. A., and Guckian, J. C., Archives of Internal Medicine, 1967, $120,63$.

4 Buchanan, C. S., and Haserick, J. R., Archives of Dermatology, 1970, 101, 664.

St. John's Hospital for Diseases of the Skin, London WC2H 7BJ ALASTAIR CARRUTHERS, M.A., M.R.C.P., Senior Registrar

Moorfields Eye Hospital, London EC1V 2PD

JEAN CARRUTHERS, M.D., Registrar

PETER WRIGHT, F.R.C.s., Consultant Ophthalmic Surgeon

\section{Miliary Tuberculosis Presenting with Skin Lesions}

Recently the incidence of miliary tuberculosis has decreased and the mean age of affected patients has increased. ${ }^{1}$ Within this older population the disease may present in a "cryptic" form and the diagnosis is often delayed or not considered. We report the unusual case of a young adult with miliary tuberculosis whose illness was ushered in by cutaneous lesions, which enabled us to make an early and unequivocal diagnosis.

\section{Case Report}

The patient, a 20-year-old girl, had come from India two years earlier and presented with painful cutaneous nodules affecting both hands which had appeared in crops over three weeks. During the week before admission she became generally unwell with sweating, shivering, anorexia, and headache. There was no known contact with tuberculosis or past history of the disease. About a dozen tender bluish-red nodules up to $5 \mathrm{~mm}$ in diameter, one of which had ulcerated, were scattered over the palms and fingers (see fig.). Apart from fever (temperature $39^{\circ} \mathrm{C}$ ) there were no other signs and, in particular, no choroidal tubercles.

Biopsy of one nodule showed foci of caseating granulomata with many acid- and alcohol-fast bacilli together with obliterative vasculitis of dermal arterioles. Chest $x$-ray examination showed miliary mottling throughout both lung fields but no primary tuberculous focus. Mantoux test 1/1000 was strongly positive. Investigation of the cerebrospinal fluid (C.S.F.) confirmed meningeal involvement; representative values were as follows: white cells (predominantly lymphocytes) $0.057 \times 10^{9} / 1$; glucose $0.72 \mathrm{mmol} / 1$ (13 $\mathrm{mg} / 100 \mathrm{ml}$ ); and protein $0.8 \mathrm{~g} / \mathrm{l}$. No web was seen, and no organisms were seen on Ziehl-Neelsen staining. Other abnormal results were an erythrocyte sedimentation rate of $32 \mathrm{~mm} / \mathrm{h}$, haemoglobin $9.6 \mathrm{~g} / \mathrm{dl}$, and serum aspartate aminotransferase $38 \mathrm{IU} / 1$. Mycobacterium tuberculosis sensitive to the full range of antituberculous drugs was subsequently grown from the skin specimen, but microscopy and culture for acid- and alcohol-fast bacilli proved negative from the bone marrow and faeces and multiple samples of sputum, early morning urine concentrates, and C.S.F.

Treatment with streptomycin $0.75 \mathrm{~g}$ intramuscularly three times weekly, rifampicin $450 \mathrm{mg} /$ daily and isoniazid $300 \mathrm{mg} /$ daily was begun on the day of admission and, apart from deterioration during the first week with signs of

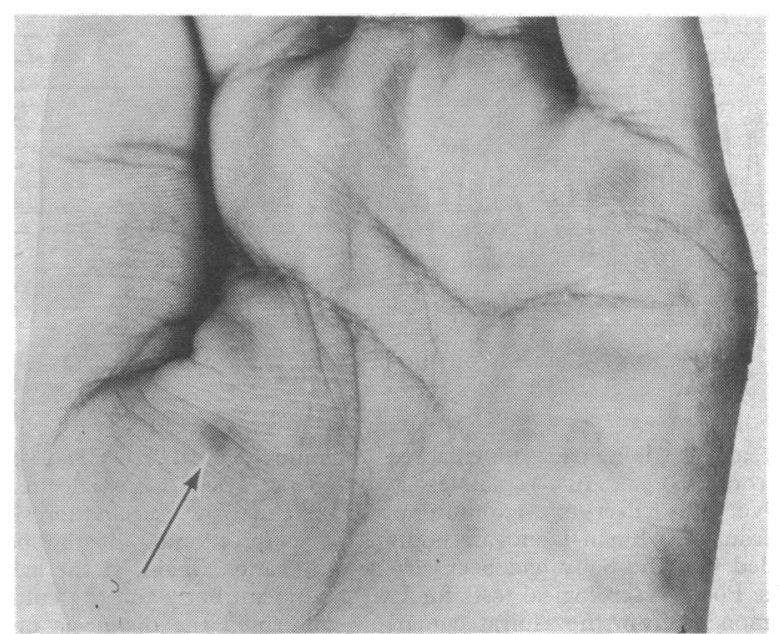

Left hand showing skin lesions over hypothenar eminence and further lesion over thenar eminence (arrowed).

progressive meningeal inflammation and vomiting which responded to a short course of prednisone, her recovery was excellent. Five months later the skin lesions were barely visible, the chest $x$-ray picture had cleared, and the C.S.F. abnormalities were resolving.

\section{Discussion}

Before the introduction of antituberculous chemotherapy various cutaneous lesions were seen during the course of miliary tuberculosis including macular, papular, vesicular, purpuric, and haemorrhagic bullous eruptions, but such lesions did not occur very often. ${ }^{2}$ This was perhaps surprising considering the haematogenous dissemination of organisms and multiple organ involvement characteristic of this condition. The only skin lesions described in recent cases have been solitary and usually related to underlying suppurative foci. ${ }^{34}$ Our patient's morphological picture bore a strong resemblance to the condition "tuberculosis cutis miliaris acuta generalisata," wellrecognized among the prechemotherapy childhood cases but only rarely encountered in adults, either then or now. ${ }^{5}$ These cases almost invariably had a fatal outcome, and skin lesions tended to appear in the later stages of the infection.

We therefore draw attention to the cutaneous abnormalities which may not only accompany but even precede other evidence of miliary tuberculosis. Since material from conventional sources in this condition is often negative on direct smear for acid- and alcohol-fast bacilli all suspected cases of miliary tuberculosis should be carefully examined for skin lesions as a possible aid to diagnosis.

We thank Dr. J. A. Hickman, Dr. J. S. Pegum, and Dr. H. Baker for advice in the preparation of the manuscript and for permission to report a patien under their care. We also thank Dr. J. W. Landells for histological details and Miss T. Carter for secretarial help.

1 Lancet, 1970, 1, 985.

2 Wilkinson, D. S., in Textbook of Dermatology, ed. A. Rook, D. S. Wilkinson, and F. J. G. Ebling, 2nd edn., p. 617. Oxford, Blackwell Scientific Publications, 1972.

3 Munt, P. W., Medicine, 1971, 51, 139.

4 Sahn, S. A., and Neff, T. A., American Fournal of Medicine, 1974, 56, 495.

${ }^{5}$ Schermer, D. R., et al., Archives of Dermatology, 1969, 99, 64.

The London Hospital, London E1 1BB

C. KENNEDY, M.B., M.R.C.P., Dermatology Registrar

G. K. KNOWLES, M.B., M.R.C.P., Medical Registrar 